\title{
On Designing Blended Learning Environments for Resource-Challenged Communities
}

\author{
https://doi.org/10.3991/ijet.v14i12.10320 \\ Shaimaa Lazem $\left({ }^{\varpi}\right)$ \\ City of Scientific Research and Technological Applications, Alexandria, Egypt \\ slazemesrtacity.sci.eg
}

\begin{abstract}
The growth of Information and Communication Technologies adoption in emerging economies and more broadly Resource-Challenged Communities (RCC) motivates the exploration of Blended Learning (BL); a learning mode that mixes face-to-face and technology-mediated instruction. BL has the potential of broadening accessibility to quality learning anytime and anywhere. This article contributes a theoretical perspective about designing BL environments in RCC. It synthesizes findings from BL literature and lessons distilled from technology projects in RCC to envision a pathway forward that consists of three design heuristics to help designers address the contextual challenges in RCC. The heuristics are: localizing the design problem, embracing the complex and nuanced use of technology, and balancing autonomy and scaffolding to support students.
\end{abstract}

Keywords-Blended Learning, ICT4D, Resource-Challenged Communities

\section{Introduction and Background}

The growth of Information and Communication Technologies (ICT) adoption in developing economies motivates exploring innovative designs for learning environments to ensure an inclusive access to quality education. Blended Learning (BL) is "a formal education program in which a student learns at least in part through online delivery of content and instruction with some element of student control over time, place, path, and/or pace and at least in part at a supervised brick-and-mortar location away from home."[1]. BL is not a mere division of content between the two delivery mediums. Rather, it aims at reaching a "harmonic" balance, between face-to-face and technology-mediated teaching [2]. It therefore requires re-thinking and reconceptualizing of the teaching pedagogy and material in light of the available resources [3], [4]. The increased interest in applying BL is grounded in empirical studies that have demonstrated the positive impact of the approach. The meta-analysis revealed that $\mathrm{BL}$ was more effective than online and face-to-face learning modes [5]. Werth et al., [6] surveyed 145 teachers, all of which have received some professional training in BL, and found that BL improved the students' willingness to take responsibility for their own learning and locate their own resources. The teachers reported that BL helped them in classroom management and increased their confidence and self- 
efficacy. Self-pacing was found to be positively correlated with the quality of a students' work, their interest and excitement during instruction as well as perseverance. In [7], BL was used to improve lecture delivery in large classrooms by shifting part of the course to an online personalized learning system and utilizing lecture time to extend students' understanding.

BL distinguishes itself by being an approach and not one way for integrating technology into classrooms. Thus, it could adapt itself to different settings, students, and content [8]. [9] provides a classification for the different models by which BL could be implemented. In the Rotation model, students rotate between learning modalities (e.g., classroom instruction, group projects, individual tutoring), where one of those modalities is online. In the flex model, the instruction is provided online, and students have customized experiences and schedules. The teachers provide face-to-face support as needed through group activities and individual tutoring. The self-blend model is where students take some courses at a school and others online, and teachers provide support as needed Online. In the Enriched-Virtual programs, students learn online within each course and attend school but not daily. This flexibility is particularly useful in developing countries, where the adoption of BL approaches could lead to a cost-effective utilization of their limited ICT and human resources. For instance, a flipped classroom model could be used to scaffold students who take online courses [10]. BL courses could be a platform for cross-national training, providing access to global experts with minimal disruption to students' schedule [11].

Designing a BL environment is not without challenges [12], [13]. It is worth noting that the term BL designers in this article does not refer to teachers who integrate ICT tools in their practice, but rather to those who are responsible for making decisions about the nature and features of classroom technology. Boelens et al., [12] identified four key challenges that face BL designers. First, flexibility is a challenge because of the numerous alternatives by which a BL experience could be designed. BL designers have to make informed decisions based on the available resources and the improvements in the learning experience they seek to achieve. Second, the large psychological and communication space that results from the increased flexibility in time and space, increases the difficulty of social interaction. BL designers should explore ways to facilitate the interaction in online learning to maintain students' social presence and sense of belonging to the course [14]. Third, scaffolding should be provided to students to help them become independent learners in BL settings. This is particularly important if the students are accustomed to teacher-centered learning. Fourth, students' isolation due to the limited social interaction could impact their motivation to learn. BL designers are encouraged to explore ways to create motivating climate for the students.

The term resources in Resource-Challenged Communities (RCC), in the context of this article, refer to four categories of resources that were identified as enablers of ICT for education projects [15]: physical resources (i.e., computers), digital resources (i.e., digital material), human resources (i.e., trained teachers), and social resources (i.e., community, institutional, and societal structures that support access to ICT). RCC face challenges in one or more of these dimensions. For instance, the limited access to 
technology devices or the Internet, the lack of qualified teachers or proper teachers' training programs, and the disadvantaged socio-economic background of the students.

It is not uncommon for institutions who wish to adopt BL in RCC to focus on increasing access to technology through initiatives that aim at providing computing devices for every student, using digital learning management systems, or transforming all courses to be delivered online [16]. Literature shows that such emphasis on access to technology is bound to fail if it does not account for the contextual factors in RCC. Students, as argued by Bourdieu [17], bring a particular social, economic, and cultural capital to their studies that empower or disadvantage them, and affect their digital literacy [18]. The presence of the computing equipment cannot by itself account for the digital know how of the student [18]. Holley and Oliver [19] researched the experience of university students, who experienced financial hardships, in a BL program. The program flexibility required the students to negotiate their needs, and to put extra effort to define their learning spaces, which were shaped by their ability to control technology, and managing their learning space at home. Vareberg [20] reported teachers' perspectives in a rural school about adopting BL. The teachers perceived technology as useful in engaging students, but they were hesitant to change or adopt new pedagogical approaches to integrate it in their classroom. Barriers such as time, training, and equipment, which are more salient in rural settings, affected their willingness to change their practice. The lack of training negatively affected their confidence, and made some of them feel physically and mentally incapable of integrating technology. This is in line with findings from [21], where factors such as age, training, and previous experiences with technology affected the teachers buy-in for the one device per child (1:1) model. Successful integration of ICT is more work on the part of the teachers, and they have to be willing to experiment with novel uses of technology. Further, the teachers become reluctant if the extra effort is not rewarded by their institutes [22].

In the past decade, a relatively small number of studies has researched BL implementations in RCC, mostly addressing BL in higher education [14], [22]-[26], and unsurprisingly revealing important barriers related to policy, technology infrastructure, training, and reluctance towards technology adoption. This article is an attempt to envision a pathway forward for designing BL environments in RCC. It takes a step back to interrogate two widely implemented projects in RCC, which had educational premises similar to BL. The One Laptop per Child (OLPC) [27], and the Hole in the Wall (HITW) [28] projects have promoted students' autonomy and personalized learning with the help of computers, which is one of the main ethos of BL. The article further examines the literature researching technology use at home in RCC, which is another fundamental factor that influences BL implementations. Informed by lessons from the literature, the article proposes three design heuristics, as a manifesto for BL designers to ensure that the particularities of RCC are not overlooked. 


\section{ICT for Education Implementations in RCC}

\subsection{One laptop per child (OLPC)}

The OLPC project produced and provided cheap, colorful 1:1 laptops to young children ages six to twelve [27]. It conceptualized learning as a student-centered, selfdirected process, where the laptop helps the child think, and where the teacher is a facilitator or co-learner. The emphasis on the child and the technology was meant to mitigate the absence of qualified teachers in developing countries, and therefore the project downplayed the value of teachers' training and curriculum support [29]. Many OLPC implementations in US had shown improvements in students learning outcomes [30], [31], but mostly in well-run and well-funded schools [32]. Other implementations, in developing countries or in underperforming schools in the US, were less successful [29], [33]. OLPC was criticized for its techno-centrism or its focus on the device more than the context. It lacked a holistic approach that takes into consideration the contextual challenges such as the infrastructure, teacher training, and pedagogy [29]. For instance, in Peru, $43 \%$ of students did not bring their OLPC as their parents feared they would be held responsible if anything happened to the device, and many poor families could not afford repairing the laptop when it broke [29]. The limitations of the OLPC approach to improve education were echoed in other studies that scrutinized the impact of 1:1 initiatives in Europe and K-12 systems [21], [34]. Examining a wide range of implementations showed that equipment provision is not sufficient to achieve transformational effects on education and that more research is required to understand the deep learning practices of students using their own devices [34]. Similarly, Harper and Milman [21] argued, based on examining 10 years of empirical research of 1:1 and K-12 education, that the question is no longer about the effect of 1:1 on students, it is rather the how, why, and under what conditions that impact is achieved.

\subsection{Hole in the wall experiments (HITW)}

Advocating a teacher-less learning model in favor of the technology motivated Sugata Mitra's HITW in India [28]. Mitra left an unattended computer fixed to a slum wall in India, where he found that the slum children had learned how to use the computer and the Internet on their own. The initial results were confirmed through empirical research in rural India between 1999 and 2006. Documented experiments showed that the children who used the HITW achieved comparable scores to students who studied school computing curriculum [35]. HITW kiosks showed, in a longitudinal study, a significant impact on mathematics achievement [36]. Further research demonstrated that Tamil speaking children in a remote Indian village were able to learn basic molecular biology in English, initially on their own and later with a mediator without subject knowledge, and found evidence that these children could reach similar levels of learning as children in formal schools [37]. Dangwal and Thounaojam [38] explained that HITW children adopted self-regulatory learning 
strategies. The strategies were correlated with self-motivation that derived the children to determine their learning goals, plan, observe, and evaluate their behavior.

Mitra later developed the concept of Self-Organized Learning Environments (SOLE), to capitalize on the lessons learned from his early HITW experiments, and expand his experiments to include schools in UK and other countries [39]. The new context offered different challenges such as allowing mixed-aged groups inside school settings, organizing the learning space to enable group work, and changing the classroom dynamics by requesting that teachers defer from intervening in students' explorations. Initial results did not mirror the success of the HITW experiments suggesting that more work is needed to appropriate SOLE to developed contexts.

\subsection{Technology use outside the classroom in RCC}

Children's use of ICT at home in RCC is understudied [40]. Research shows that family support is a predictor of computer use, and that family members act as mediators to appropriate technologies [40], [41]. Nogry [40] examined computer use in a village in Madagascar that was involved in an OLPC project for four years. Parents, siblings, and peers were also using the laptop with the children, and its use was subject to house rules such as balancing doing homework and playing games. Computer use was different from what was intended by its designers as the laptops were used as mediums for self-expression through the use of photo and video applications. Children did not use it individually, and used it mostly for drill and practice rather than material production of original projects or artifacts. That digital production gap suggests that scaffolding by teachers is a necessity to foster creativity in RCC. Uchidiuno et al., [42] explored the tablet use in rural Tanzania in school and at home. The students in her study did not immediately help each other with unknown domain knowledge. The presence of adults changed the dynamics as children preferred to resort to them, and they waited for them to leave so they could help each other. Children were less resilient and persistent and more likely to dropout at home as they lacked proper scaffolding.

The complex use scenarios outside the classroom, present a different set of challenges to BL designers that will not be solved by providing access to a "technology device". As Stevenson puts it "...there is a need to move beyond one-dimensional debates, such as access to ICT ensures use, to more nuanced accounts that focus on the "messy" realities of ICTs usage "as it happens" in the home." [41].

\section{Envisioning a Pathway forward}

This section suggests a pathway forward for BL designers that is inspired by the lessons learned from the presented literature. Unlike the approaches that fit BL design around a certain technology, three design heuristics are proposed to help BL designers recognize the contextual challenges in RCC from the outset, and address them as they make choices in terms of the type of technology, and its integration in classrooms. 


\subsection{Localization}

BL Designs that are grounded in the understanding of the local reality are more likely to succeed. HITW and OLPC reflected the culture of their designers. While HITW reflected a collective view of ownership and knowledge sharing that is common in India, OLPC ownership and its 1:1 model reflected an individualism perspective that tends to prevail in developed and Western countries [43]. The significant improvements achieved by both projects in their native context were challenged in other cultural settings such as the applications of HITW in UK, or Tanzania [39], [42], and OLPC implementations in RCC. Contrary to the notorious disappointing results of the OLPC in Peru, a successful local project emerged in rural Peru for a charity that distributed refurbished desktop computers to schools [33]. The project success was attributed to understanding the local context and the use of a bottom up approach through which the community was empowered and various stakeholders were involved in setting the program agenda. It is thus argued that BL designers should localize the design problem by understanding the context of the community, school, teachers, and students including their use of technology at home.

\subsection{Embracing the complex realities}

While localization focuses on understanding the local context, embracing the complex realities is concerned with how this understanding is enacted in the design. BL designers could see the limitations of available resources as opportunities to provide novel alternatives. HITW implementation in India succeeded in embracing the collective use of technology to foster peer learning. Another example is BingBee, an information kiosk that was designed in South Africa, where a computer was fully contained behind a shop window to avoid vandalism [44]. Street kids accessed the computer by tracking their fingers on an inexpensive fabric externally mounted on the shop window. Providing individual access to technology is not the only way to implement BL. Students could share access in school lab using a BL rotation model [9]. Moreover, if family members dominate the technology use at home, BL designers might consider including them as stakeholders in the design process [42].

\subsection{Balancing autonomy and scaffolding}

The students' autonomy is one of the ethos of BL. Littlewood [45] conceptualized autonomy as a spectrum that ranges between proactive and reactive autonomy. In proactive autonomy, the learners set the goals, pursue them by making their own choices, evaluate their progress, and adjust accordingly. Reactive autonomy is when directions are not set by the learners, but once they are set, learners make decisions and choices regarding appropriate and necessary resources to achieve those goals. Reactive autonomy could be more appropriate for implementing BL in RCC, where research shows that students might show less resilience in absence of proper scaffolding at home or at school [42]. A BL in RCC could be a space, where students engage in learning activities and negotiate autonomy while time, resources and directions are 
set and monitored by the teacher [46]. Vygotsky's zone of proximal development concept, explains that there is stage that a learner cannot progress without support from a capable adult or peer [46]. Scaffolding should be provided when needed by teachers, or with help from peers such as in the HITW project. Technology could provide scaffolding by providing automated feedback. Further, digital learning analytics could be used to tune the content and delivery to the students' individual paces and draw the teacher's attention to underperformed students [47].

\section{Conclusions and Future Work}

The flexibility of the BL approach holds many promises for RCC as learning becomes a personalized experience centered around students' needs and abilities, and one that makes a cost-effective use of the community constrained resources. Instead of discussing the effectiveness the BL environment based on certain technology features, this article took a step back to inform the design of BL environments by lessons learned from previous technology implementations in RCC. It introduced three highlevel design heuristics for BL designers to help them think about the contextual factors in RCC. Future work will investigate the operationalization of the introduced heuristics in the presence of practical barriers such as the lack of supporting fund to implement the heuristics; and identify fine-grained design guidelines for BL in RCC.

\section{$5 \quad$ References}

[1] Staker, H., \& Horn, M. B. (2012). Classifying K - 12 blended learning. Innosight Institute, (May), 22. http://doi.org/10.1007/s10639-007-9037-5

[2] Osguthorpe, R. T., \& Graham, C. R. (2003). Blended Learning Environments: Definitions and Directions. Quarterly Review of Distance Education, 4(3), 227-33.

[3] Garrison, D. R., \& Kanuka, H. (2004). Blended learning: Uncovering its transformative potential in higher education. Internet and Higher Education, 7(2), 95-105. https://doi.org/10.1016/j.iheduc.2004.02.001

[4] Cacho, R., Avila, R., \& Villaseñor, E. (2017). “What's the Tab's Apps?’: Piloting LowPriced-Tablet-Aided Course Delivery in Teacher Education. International Journal of Emerging Technologies in Learning (IJET), 12(10), 95-111. https://doi.org/10.3991/ijet.v12i10.7162

[5] Means, B., Toyama, Y., Murphy, R., Bakia, M., \& Jones, K. (2010). Evaluation of Evidence-Based Practices in Online Learning: A Meta-Analysis and Review of Online Learning Studies. US Department of Education. Retrieved from: http://eric.ed.gov/?id=ED505824

[6] Werth, E., Werth, L., \& Kellerer, E. (2013). Transforming K-12 Rural Education through Blended Learning: Barriers and Promising Practices. International Association for K-12 Online Learning. Retrieved from: http://search.ebscohost.com/login.aspx?direct=true\&db $=$ eric\&AN $=$ ED561276\&site $=$ ehost-live

[7] McKenzie, W. A., Perini, E., Rohlf, V., Toukhsati, S., Conduit, R., \& Sanson, G. (2013). A blended learning lecture delivery model for large and diverse undergraduate cohorts. Computers and Education, 64, 116-126. http://doi.org/10.1016/j.compedu.2013.01.009 
[8] Osguthorpe, R. T., \& Graham, C. R. (2003). Definitions and directions. Quarterly Review of Distance Education, 4(3), 227-233.

[9] Staker, H., \& Horn, M. B. (2012). Classifying K - 12 blended learning. Innosight Institute, 22. Retrieved from https://eric.ed.gov/?id=ED535180

[10] Santikarn, B., \& Wichadee, S. (2018). Flipping the Classroom for English Language Learners: A Study of Learning Performance and Perceptions. International Journal of Emerging Technologies in Learning (IJET), 13(09), 123-135. https://doi.org/10.3991/ijet.v13i09.7792

[11] Protsiv, M., Rosales-Klintz, S., Bwanga, F., Zwarenstein, M., \& Atkins, S. (2016). Blended learning across universities in a South-North-South collaboration: A case study. Health Research Policy and Systems, 14(1). http://doi.org/10.1186/s12961-016-0136-X

[12] Boelens, R., De Wever, B., \& Voet, M. (2017). Four key challenges to the design of blended learning: A systematic literature review. Educational Research Review, 22(June), 1-18. https://doi.org/10.1016/j.edurev.2017.06.001

[13] Ismail, A., Mahmood, A., \& Abdelmaboud, A. (2018). Factors Influencing Academic Performance of Students in Blended and Traditional Domains. International Journal of Emerging Technologies in Learning (IJET), 13(02), 170-187. https://doi.org/10.3991/ijet.v13i02.8031

[14] Almasi, M., \& Zhu, C. (2018). Students' Perceptions of Social Presence in Blended Learning Courses in a Tanzanian Medical College. International Journal of Emerging Technologies in Learning (IJET), 13(09), 107-122. https://doi.org/10.3991/ijet.v13i09.8566

[15] Warschauer, M. (2003). Dissecting the "Digital Divide": A Case Study in Egypt. Information Society, 19(4), 297-304. http://doi.org/10.1080/01972240309490

[16] Barbour, M. K. (2014). A history of international K-12 online and blended instruction. In Handbook of Research on K-12 Online and Blended Learning (p. 516). Retrieved from http://dl.acm.org/citation.cfm?id=2811039

[17] Ignatow, G., \& Robinson, L. (2017). Pierre Bourdieu: theorizing the digital. Information Communication and Society, 20(7), 950-966. https://oi.org/10.1080/1369118x.2017.1301519

[18] Prasad, P. W. C., Maag, A., Redestowicz, M., \& Hoe, L. S. (2018). Unfamiliar technology: Reaction of international students to blended learning. Computers \& Education, 122, 92103. http://doi.org/10.1016/J.COMPEDU.2018.03.016

[19] Holley, D., \& Oliver, M. (2010). Student engagement and blended learning: Portraits of risk. Computers and Education, 54(3), 693-700. https://doi.org/10.1016/j.compedu.2009.08.035

[20] Vareberg, K. R. (2016). It's easy until it's not: Elements contributing to rural teachers' technology use. Retrieved from https://search.proquest.com/docview/1813333502?accountid=12753

[21] Harper, B., \& Milman, N. B. (2016). One-to-one technology in K-12 classrooms: A review of the literature from 2004 through 2014. Journal of Research on Technology in Education, 48(2), 129-142. http://doi.org/10.1080/15391523.2016.1146564

[22] Rizvi, N. F., Gulzar, S., Nicholas, W., \& Nkoroi, B. (2017). Barriers in adopting blended learning in a private university of Pakistan and East Africa: faculty members' perspective. MHealth, 3(5). http://doi.org/10.21037/mhealth.2017.04.04

[23] Tshabalala, M., Ndeya-Ndereya, C., \& van der Merwe, T. (2014). Implementing blended learning at a developing university: Obstacles in the way. Electronic Journal of ELearning, 12(1), 101-110. 
[24] Atef, H., \& Medhat, M. (2015). Blended learning possibilities in enhancing education, training and development in developing countries: A case study in graphic design courses. TEM Journal, 4(4), 358-365.

[25] Nkhukhu-Orlando, E. (2015). Technological Changes at the University of Botswana: Academics and Blended Learning. In Proceedings of the 4th European Conference on Rlearning (ECEL 2015) (pp. 730-736).

[26] Voeller, J. (2017). A Case Study: Developing a Micro-College Model Using MOOCs for an Underserved Community. In 2017 International Symposium on Educational Technology (ISET) (pp. 212-216). http://doi.org/10.1109/ISET.2017.56

[27] One Laptop Per Child. (n.d.). Retrieved Mar 11, 2019, http://one.laptop.org/about/mission

[28] Hole in the Wall Education Project. (n.d.). Retrieved March 11, 2019, http://www.hole-inthe-wall.com

[29] Warschauer, M., Cotten, S., \& Ames, M. (2011). One Laptop per Child Birmingham: Case Study of a Radical Experiment. International Journal of Learning and Media, 3(2), 61-76. https://doi.org/10.1162/ijlm a 00069

[30] Suhr, K. A., Hernandez, D. a, Grimes, D., \& Warschauer, M. (2010). Laptops and fourthgrade literacy: Assisting the jump over the fourth-grade slump. Journal of Technology, Learning, and Assessment, 9(5), 1-46.

[31] Warschauer, M. (2010). Learning to Write in the Laptop Classroom. Writing \& Pedagogy, 1(1), 101-112. http://doi.org/10.1558/wap.v1i1.101

[32] Toyama, K. (2011). There are no technology shortcuts to good education. http://edutechdebate.org/ict-in-schools/there-are-no-technology-shortcuts-to-goodeducation/

[33] Therias, E., Bird, J., \& Marshall, P. (2015). Más Tecnología, Más Cambio ? Investigating an Educational Technology Project in Rural Peru. In International Conference on Human Factors in Computing Systems (pp. 447-456). http://doi.org/10.1145/2702123.2702595

[34] Bocconi, S., Kampylis, P., \& Punie, Y. (2013). Framing ICT-enabled Innovation for Learning: The case of one-to-one learning initiatives in Europe. European Journal of Education, 48(1), 113-130. http://doi.org/10.1111/ejed.12021

[35] Mitra, S. (2005). Self organising systems for mass computer literacy: Findings from the 'hole in the wall' experiments. International Journal of Development Issues, 4(1), 71-81. https://doi.org/10.1108/eb045849

[36] Inamdar, P., \& Kulkarni, A. (2007). "Hole-in-the-wall” computer kiosks foster mathematics achievement - A comparative study. Educational Technology and Society, 10(2), 170179.

[37] Mitra, S., \& Dangwal, R. (2010). Limits to self-organising systems of learning - The Kalikuppam experiment. British Journal of Educational Technology, 41(5), 672-688. https://doi.org/10.1111/j.1467-8535.2010.01077.x

[38] Dangwal R and Thounaojam M. (2011). Self Regulatory Behaviour and Minimally Invasive ( MIE ) Education: A Case study in the Indian Context. International Journal Of Nal of Education and Development Using ICT, 7(1), 120-140.

[39] Rix, S., \& McElwee, S. (2016). What happens if students are asked to learn Geography content, specifically Population, through SOLE? Other Education: The Journal of Educational Alternatives, 5(1), 30-54.

[40] Nogry, S., \& Varly, P. (2018). Everyday Laptop Use by Children in a Southern Country: A Mixed-Method Approach. Journal of Research on Technology in Education, 50(1), 18-33. https://doi.org/10.1080/15391523.2017.1388200 
[41] Stevenson, O. (2011). From public policy to family practices: Researching the everyday realities of families' technology use at home. Journal of Computer Assisted Learning, 27(4), 336-346. http://doi.org/10.1111/j.1365-2729.2011.00430.x

[42] Uchidiuno, J., Yarzebinski, E., Madaio, M., Maheshwari, N., Koedinger, K., \& Ogan, A. (2018). Designing Appropriate Learning Technologies for School vs Home Settings in Tanzanian Rural Villages. In Proceedings of the 1st ACM SIGCAS Conference on Computing and Sustainable Societies. http://doi.org/10.1145/3209811.3209881

[43] Hofstede, G. (2011). Dimensionalizing Cultures: The Hofstede Model in Context. Online Readings in Psychology and Culture, 2(1). http://doi.org/10.9707/2307-0919.1014

[44] Wentworth, P. (2010). BingBee@ RaglanRoad - A field trial with unattended educational kiosks. In IST-Africa, 2010 (pp. 1-8).

[45] Littlewood, W. (1996). "Autonomy": An anatomy and a framework. System, 24(4), 427435. http://doi.org/10.1016/S0346-251X(96)00039-5

[46] Snodin, N. S. (2013). The effects of blended learning with a CMS on the development of autonomous learning: A case study of different degrees of autonomy achieved by individual learners. Computers and Education, 61(1), 209-216. https://doi.org/10.1016/i.compedu.2012.10.004

[47] Lazem, S., \& Jad, H. A. (2017). We Play We Learn: Exploring the Value of Digital Educational Games in Rural Egypt. In Proceedings of the 2017 ACM Conference on Human Factors in Computing Systems (pp. 2782-2791). http://doi.org/10.1145/3025453.3025593

\section{Author}

Shaimaa Lazem is an Egyptian academic. She earned her $\mathrm{PhD}$ in Computer Science from Virginia Tech, USA. Her research interests include designing educational technologies and computer science education in resource-challenged communities. She was awarded the Leaders in Innovation Fellowship with the Royal Academy of Engineering in London to support digital self-documentation of intangible cultural heritage.

Article submitted 2019-02-14. Resubmitted 2019-03-13. Final acceptance 2019-05-21. Final version published as submitted by the authors. 